\title{
National Enhanced Elevation Assessment at a Glance
}

\section{Introduction}

Elevation data are essential for hazards mitigation, conservation, infrastructure development, national security, and many other applications. Under the leadership of the U.S. Geological Survey and the National Digital Elevation Program (NDEP), Federal agencies, State agencies, and others work together to acquire high-quality elevation data for the United States and its territories. New elevation data are acquired using modern technology to replace elevation data that are, on average, more than 30 years old. Through the efforts of the NDEP, a project-by-project data acquisition approach resulted in improved, publicly available data for 28 percent of the conterminous United States and 15 percent of Alaska over the past 15 years. Although the program operates efficiently, the rate of data collection and the typical project specifications are currently insufficient to address the needs of government, the private sector, and other organizations.

The National Enhanced Elevation Assessment (NEEA; Dewberry, 2011) was conducted to (1) document national-level requirements for improved elevation data, (2) estimate the benefits and costs of meeting those requirements, and (3) evaluate multiple national-level programimplementation scenarios. The assessment was sponsored by the NDEP's member agencies. The study participants came from 34 Federal agencies, agencies from all 50 States, selected local government and Tribal offices, and private and not-for-profit organizations. A total of 602 missioncritical activities were identified that need significantly more accurate data than are currently available. The results of the assessment indicate that enhanced elevation data have the potential to generate $\$ 13$ billion in new benefits annually.

\section{Requirements for Enhanced Elevation Data}

The requirements for elevation data were documented as part of the assessment through surveys and structured interviews. Each requirement was described in terms of the accuracy of the data, the data refresh cycle, and the geographic area of interest. The expected benefits that would result from meeting these requirements were also identified. To facilitate this analysis, the results of the survey and interviews were sorted by 27 predefined business uses. Table 1 summarizes expected benefits for the top 10 of 27 identified business uses, in dollar amounts. The dollar amounts represent cost savings either for the operating agencies or for the customers who use their services and are detailed for each organization in Dewberry (2011). For example, in Alabama, high-quality elevation data could potentially save the State's Department of Economic and Community Affairs \$5 million because of the reduced time (and thereby costs) needed to create datasets for analyzing flood risks. The improved data could potentially save the agency's customers $\$ 3$ million because the data would help reduce the costs and amount of time required to complete certain phases of flood-risk mitigation projects.

For about half of the reported applications, the surveyed organizations were unable to identify specific economic benefits even though most of them expected major benefits from improved elevation data. For example, the Environmental Protection Agency needs high-accuracy, high-resolution topographic data to characterize the landscape for both environmental protection and assessment of ecosystem services but did not quantify the benefits. Narratives describing the benefits of improved elevation data without associated monetary benefits are also included in Dewberry (2011).

\section{Analysis and National Elevation Program Scenarios}

Benefit-cost analyses were developed and examined for more than 25 program scenarios (Dewberry, 2011), which included various quality levels for the elevation data (table 2) and datareplacement cycles. The estimated costs for each scenario include those for data collection and life-cycle management.

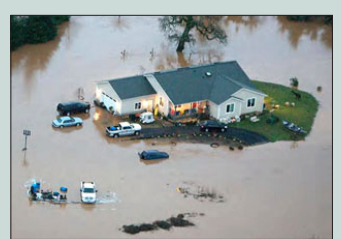

Flood risk management

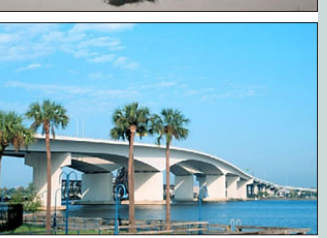

Infrastructure management

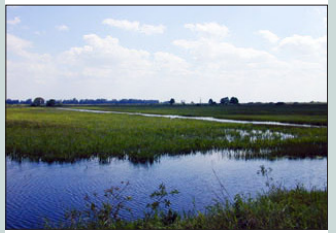

Natural

resources

conservation

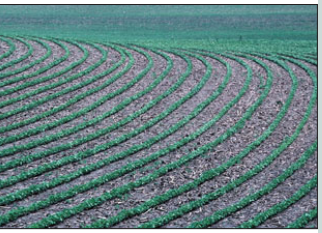

Agriculture and precision farming

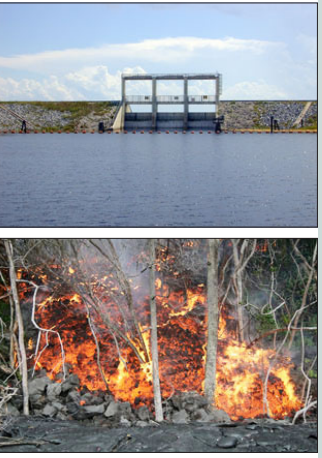

Water supply

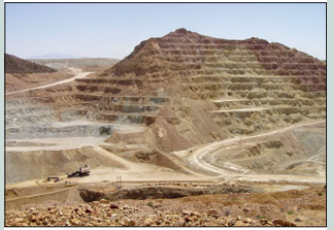

Wildfire management
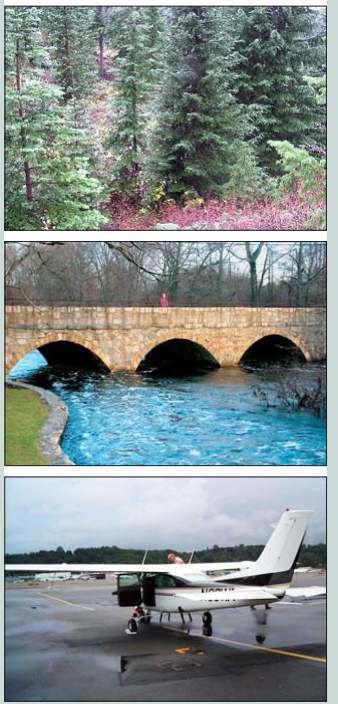

Forest resources management

Stream resource management

Geologic resource assessment

Aviation safety 
Table 1. Annual aggregated monetary benefits for the top 10 business uses identified in the National Enhanced Elevation Assessment.

[Benefits were reported as single values or as a range of values in the assessment report (Dewberry, 2011). Only one half of participants were able to assign benefits to their activities, and the conservative benefits include these numbers only. Further, when benefits were reported as a range, only the low end of the range was included in calculating conservative benefits. Potential benefits were based on the high end of benefit ranges and included some estimated and projected benefits as well as the benefits expected from some emerging applications]

\begin{tabular}{|c|c|c|c|}
\hline \multirow[b]{2}{*}{ Rank } & \multirow[b]{2}{*}{ Business use } & \multicolumn{2}{|c|}{ Annual benefits } \\
\hline & & $\begin{array}{c}\text { Conservative } \\
\text { (in millions of } \\
\text { dollars) }\end{array}$ & $\begin{array}{c}\text { Potential } \\
\text { (in millions of } \\
\text { dollars) }\end{array}$ \\
\hline 1 & Flood risk management & $\$ 295$ & $\$ 502$ \\
\hline 2 & Infrastructure and construction management & 206 & 942 \\
\hline 3 & Natural resources conservation & 159 & 335 \\
\hline 4 & Agriculture and precision farming & 122 & 2,011 \\
\hline 5 & Water supply and quality & 85 & 156 \\
\hline 6 & Wildfire management, planning, and response & 76 & 159 \\
\hline 7 & Geologic resource assessment and hazard mitigation & 52 & 1,067 \\
\hline 8 & Forest resources management & 44 & 62 \\
\hline 9 & River and stream resource management & 38 & 87 \\
\hline 10 & Aviation navigation and safety & 35 & 56 \\
\hline
\end{tabular}

Each scenario would implement a national data-collection strategy to achieve cost efficiencies and meet the requirements of multiple organizations.

The final analysis yielded 10 leading scenarios, which are shown in figure 1. The least beneficial scenario is one that provides national data coverage at quality level 3 (see table 2 for more information on quality levels) on a 25 -year replacement schedule but realizes only 13 percent of the benefits. In contrast, the national data coverage at quality level 1 on an annual replacement schedule realizes 98 percent of the conservative benefits. The 58-percent mid-range scenario offers a good benefit-to-cost ratio, uniform quality level 2 data, and an 8-year acquisition cycle. All of the scenarios included quality level 5 data coverage in Alaska, which would be collected by using interferometric synthetic aperture radar (ifsar) techniques; in Alaska cloud cover and remoteness preclude consideration of lidar data over much of the State. With the exception of the 98-percent scenario, all of the scenarios resulted in positive benefitto-cost ratios ranging from 4:1 to 5:1 using the most conservative benefit estimates.

The NEEA also reviewed current and emerging commercial elevation-data technologies, assessed data life-cyclemanagement costs for the various scenarios, and produced an inventory of existing elevation data derived from lidar and ifsar datasets. The inventory revealed that about 28 percent of the conterminous United States is covered by quality level 3 lidar data and that about 15 percent of Alaska is covered by ifsar data.

\section{Summary}

The current NDEP activity is a partnership between Federal, State, and other agencies. Although the effort is efficient (very little duplication of effort), the program currently meets less than 10 percent of the needs identified in the NEEA. The following are the major findings:

1. Significant benefits could be realized by systematically upgrading the Nation's elevation data. Hundreds of improved business applications would benefit all levels of government and multiple industries.

2. The developed program scenarios demonstrated that favorable benefit-to-cost ratios can be achieved by integrating multiple requirements in large projects.

3. A new information technology infrastructure is needed for a project of this scale.

4. Current elevation technologies, industry capacity, data standards, and related matters are sufficient; there are
Table 2. Data quality levels used in the National Enhanced Elevation Assessment.

$[\leq$, less than or equal to]

\begin{tabular}{ccc}
$\begin{array}{c}\text { Quality } \\
\text { level }\end{array}$ & $\begin{array}{c}\text { Horizontal } \\
\text { point spacing } \\
\text { (meters) }\end{array}$ & $\begin{array}{c}\text { Vertical accuracy } \\
\text { (centimeters) }\end{array}$ \\
\hline 1 & 0.35 & 9.25 \\
2 & 0.7 & 9.25 \\
3 & $1-2$ & $\leq 18.5$ \\
4 & 5 & $46-139$ \\
5 & 5 & $93-185$ \\
\hline
\end{tabular}

no capability constraints or technical barriers precluding a national program and no technical reasons to delay its implementation.

5. The majority of applications now require data better than quality level 3 .

\section{Reference Cited}

Dewberry, 2011, Final Report of the National Enhanced Elevation Assessment: Fairfax, Va., Dewberry, 84 p. plus appendixes (revised 2012), available at http://www. dewberry.com/Consultants/Geospatial Mapping/FinalReport-National EnhancedElevationAssessment.

\section{Partners}

The NEEA was conducted under a contract between the U.S. Geological Survey and Dewberry (a consulting firm based in Fairfax, Va.). Additional support for the assessment came from other Federal agencies: the Federal Emergency Management Agency, the National Geospatial-Intelligence Agency, the National Oceanic and Atmospheric Administration, and the Natural Resources Conservation Service.

\section{For Further Information}

More information on the NEEA may be found at http://nationalmap.gov/3DEP/ neea.html, or by contacting the author at gsnyder@usgs.gov or (703)648-5169.

By Gregory I. Snyder

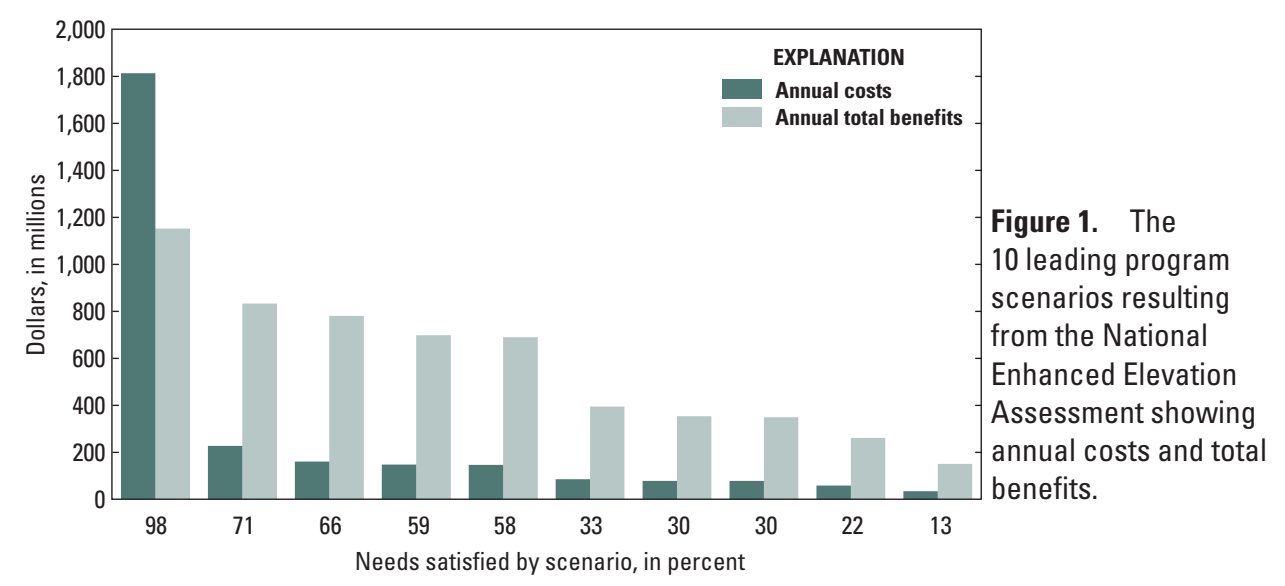

